Research Article

\title{
Perceptional Effects of Reservation Policy for The Inclusive Civil Service of Nepal
}

\section{Baburam Bhul}

Central Department of Public Administration, Tribhuvan University

Article Information
Received: 02 February 2021
Revised version received: 04 April 2021
Accepted: 07 April 2021
Published: 28 April 2021
Cite this article as:
B. Bhul (2021) Int. J. Soc. Sc. Manage. 8(2): $380-390$.
DOI: $10.3126 /$ ijssm.v8i2.34676
*Corresponding author
Baburam Bhul,
Central Department of Public Administration,
Tribhuvan University, Nepal
Email: sagarbaburam @gmail.com
Peer reviewed under authority of IJSSM
() 2021 IJSSM, Permits unrestricted use under the
CC-By-NC license.
OPEN ACCESS
This is an open access article \& it is licensed under a
International
Keywordstive Commons Attribution Non-Commercial 4.0

\begin{abstract}
This research article aims to carry out the perceptional effects of reservation policy for the inclusive civil service of Nepal with the theoretical foundation of equitable and a just society. This article adopted mixed method approach. Similarly, in order to show the linkage between primary and secondary data, content analysis was conducted from the observational notes, field notes, and responses collected by closed ended questionnaire for 130 respondents in questionnaire survey and interviews. The bivariate analysis between dependent variable and independent variable shows the effects of gender, age and education matters in inclusiveness of civil service i.e. there is high relationship between these variables. Organizational effects of reservation system have been highly significant relationship between the representativeness and participation in civil service of Nepal. This newly introduced system has been able to give some positive impacts in terms of increasing representation of some marginalized communities but has created some controversies and confusions as well. Whereas Nepalese reservation system has not still given comprehensive attention to all the dimensions of exclusion but its effects on generating attraction of some targeted marginalized people towards national bureaucratic system is literally praiseworthy.
\end{abstract}

Keywords: social inclusion; policy implementation; reservation policy; perceptional effects; civil service of Nepal

\section{Introduction}

According to the World Bank Report (2018), the aim of affirmative action or reservation policy is to correct historical disadvantages and unfair discrimination by enabling access to full opportunity and benefits to groups that have been excluded'. Affirmative action provides disadvantaged groups with access to education, formal employment and political participation, often based on quotas. The history of affirmative action or reservation system in Nepal shows back to the date of 1995 on which date the government categorized oppressed class and allocated some budget. The main reason of having reservation system was social exclusion in Nepal which has been traced back to the 14th century where King Jayashiti Malla introduced 64 vertical occupational caste groups among the Newar community. Then the act of discrimination had been started from the beginning of Muluki Ain of Nepal (1910 B.S.) which had been created enough discriminations over minority groups in the whole 
Nepalese society. Then the 'Democratic Movement II' 1 of April 2006 has been historic not only for defeating King Shah regime and declaring Nepal a Federal Democratic Republic by the first meeting of the Constituent Assembly on 28 May 2008, but also as a foundation for several inclusive policies. In the construction of an inclusive nation, affirmative action is one frequently debated issue among citizens, academics, political leaders, government officials, and activists alike. To create an inclusive civil service, the government announced the reservation policy for women, Janajati, and Dalits; however, it could not take the direction because of the government instability and lack of political commitment and support.

However, the system of representation varies across the world whereas some countries, quota for women appeared in politics as early as in the 1930s. However, few countries adopted systematic gender quotas in politics (Krook, 2010). The UN Economic and Social Council decided to reach the target of 30 percent female representation in decision making bodies by 1995 . In some OECD countries, about 50 percent of civil service position was occupied by female in 1997. In France, it was 55.9 percent in 1996 and in Australia and Canada it was 49.2 percent and 49.5 percent respectively in 1997. In United Kingdom, it was 49.1 percent and in the United States 44 percent in 1996 (OECD, 2008). In Korea it was 28.7 percent in 1997 and 40.8 percent in 2008. In some none OECD countries, in Bangladesh it was 10 percent in 2002 (Foley \& Chowdhury, 2007). In Nepal, one of the prominent steps in 2007 was, the government took several policy actions to increase the representation of women and excluded groups in political institutions and in the civil service. The recent census of 2011 has categorized 125 castes as well as ethnic communities in Nepal out of 26.5 million populations. Though Nepali speaking people count 44.6 percent of the total population, over 131 identified languages (language Commission) are spoken in Nepal and 10 types of religion are practiced. There are 21 percent of the population (Nepal Population Report, 2018) living below the poverty line. Social exclusion is known to be one of the main problems in this country. The process of exclusion has been identified to be mainly based on Hindu caste system, socio-cultural stratification and patriarchal system of the society. There is no single set of indicators of socially excluded groups till now. In order to increase minority participation in civil service, government introduced reservation system, with second amendment of Civil Service Act, for women, Ethnic groups (Adibasi), Madhesi, Dalit, disabled, and the people belonging to remote areas. Moreover, political and bureaucratic representation of these marginalized communities has been very low as compared to their proportion in population.

\section{Literature Review}

\section{Policy Implementation: Organizational Culture}

At the global level, the discussions have been dominated by first and second generations studies on policy implementation. First generation study of policy implementation involved a period of academic debate about the meaning of implementation (Hill \& Hume, 2014). Second generation studies are broadly classified into topdown (administrative) and bottom-up (participatory) approaches of policy implementation (Stewart et al., 2008). Bottom-up theorists emphasize target groups and service providers, arguing that policy really is made at the local level. Studies about public policy by various scholars are implicit on the importance of governance in public policy implementation. Reforms that seek to disconnect policy implementation from political matters may face a more difficult task than had been thought (Hicks, 2014). While theory building was not at the heart of the first generation of implementation studies, the second generation began to put forward a whole range of theoretical frameworks and hypotheses. The third generation of implementation research tried to bridge the gap between top-down and bottom-up approaches by incorporating the insights of both camps into their theoretical models. At the same time, the self-proclaimed goal of third-generation research was "to be more scientific than the previous two in its approach to the study of implementation" (Goggin et al. 1990, 18, emphasis in original). Europe was also the origin of a new strand of literature that focused on the issue of implementation in the context of European integration studies.

Van Meter and Van Horn (1975, p.471), in their framework of policy implementation, have explained the dispositions of implementers and its effect in achieving set standards and objectives of policies. The disposition is about the perception of policy implementers that may affect the application of public policies. Therefore, disposition and commitment of policy implementers can be explained as one of the broader parts of administrative culture. The theories of administrative culture are about the perception and behavior of administrative actors in the organizational operations. Therefore, Van Meter and Van Horn might not deal with the issue of disposition of policy implementers within the broader framework of administrative culture in their study. Hofstadter's study on "Cultures and Organizations" in 1991 has given the message that societal and organizational culture are essential to be considered in the policy process and we can explain the disposition of

\footnotetext{
${ }^{1}$ Democratic Movement II is a name given to the political agitations against the direct and undemocratic rule of King Gyanendra of Nepal. The movement is also sometimes referred to
}

as Jana Andolan-II ("People's Movement-II") in 2062/63, implying it being a continuation of the 1990 Janandolan I ("People's Movement-I") in 2047. 
policy implementers as an associated part of organizational culture. The study found that the commitment of administrative actors has an influence on the application of reservation system in the civil service. The word commitment is also related to ownership in order to accomplish assigned tasks. Commitment is also associated with the outlook of policy implementers. Disposition is about attitude and perception of administrative actors towards implementing public policies in their organizations. Theoretical literature on policy implementation pronounces that there is a relationship between disposition of policy implementers and effectiveness of policy implementation as argued by Van Meter and Van Horn (1975, p.472).

\section{History of the Social Exclusion}

The concept of social inclusion figured prominently in the policy discourse in France in the mid-1970s. The concept was later adopted by the European Union in the late 1980s as a key concept in social policy and in many instances replaced the concept of poverty. This concept which had first appeared in Europe as a response to the crisis of the welfare. However, it means all things to all people. The research carried out in $\mathrm{OECD}^{2}$ countries in (2014) revealed that even though quotas can increase female representation, they should serve as a transitional or correctional measure to reduce historical differences in representation. Quota effectiveness depends highly on the design of the quota and the country's electoral system. In the global context, the concept of social exclusion seems to have a very long history. However, "exclusion is as old as hills" (Oommen, 2010 , p. 1). In fact, the term exclusion is found to be described even in the Vedic Period. The caste system has been also described in the Vedic texts. According to this, the exclusion through the emergence of caste system first took place from the sacrifice of the primordial man. According to the text described in the Vedic texts Brahmins were born from the mouth of the primordial man. Similarly, the Kshetriya's were born from the shoulders and those of Vaishya's and Shudras were born respectively from the thigh and the legs/feet. The hierarchy here is shown due to inequality from mouth to legs or feet, feet being the lowest part of the body (Omvedt, 2008).

Exclusion as a subject of debate was begun in France, Europe during 1960 and the concept of the social exclusion was originated there in the early 1970s, when a French administrator referred to a variety of socially stigmatized individuals as socially excluded: the mentally and physically handicapped, aged invalids, those who survived attempted suicides, children subjected to abuse, single parents, those who indulged in substance abuse, delinquent behavior or prostitution. According to Silver (1994), the

${ }^{2}$ The Organization for Economic Co-operation and Development (OECD) is an international organization of thirtyfour countries. Member countries of OECD all have a democratic politicians, activists, officials, journalists and academicians made it vogue and ideological references to the poor as the excluded. According to Nepal Population Report (2011), in the developmental scenario and inclusion debate of Nepal, there are four groups or communities to have fallen in the area of exclusion. They are women, indigenous nationalities, Madhesi people, and Dalits. Besides, the minorities, Muslims, disable, and the third sex people are also taken as excluded groups. However, in terms of poverty stand point; there can be other groups or people who can fall in the premise of exclusion (Nepal Population Report, 2011). This argument shows that the caste hierarchy and state ideology were the main cause to the growth of the social inequality. This social inequality has caused social exclusion in Nepal keeping many castes and ethnic communities in the excluded state from socio-economic, political and several other opportunities. Moreover, the feudalistic orientation of the society also may have helped perpetuate the exclusionary process. In today's date, the discrimination by caste is considered to be against the law and it is highly punishable. However, it has not been completely eradicated from Nepalese society. Even the constitution of Nepal 1990, The Interim Constitution of Nepal 2007 and constitution of Nepal 2015 have clearly stated that the social discrimination and untouchability are as legally highly punishable (http://www.wipo.int/wipolex/en/text.jsp?file_id=189180/)

\section{Evolution of Social Inclusion}

The understanding of social inclusion will be stronger with the concept of exclusion because exclusion and inclusion are the two sides of the same coin (Francis, 1997). The meaning of inclusion is not complete without the meaning of exclusion. Indeed, the need for inclusion arises only if exclusion exists (Oommen, 2010). Therefore, exclusion and inclusion are relative terms. There exists "a sizeable grey area between social exclusion and social inclusion, and in the real world most people live most of their lives in this zone, moving closer to social exclusion and Social Inclusion at various points during their lifetime" (Figueiredo \& Gore, 1997, p. 42). Therefore, I have explained the terms exclusion and inclusion side by side. Generally, Social Inclusion is chosen in preference to social exclusion and is often used as the opposite to social exclusion; and whenever there is a discussion of Social Inclusion, the related concept of social exclusion always comes there for discussion (Bhandari, 2012). In this connection, I agree with the argument that no inclusion is necessary if there is absent of exclusion. This is also supported, in a way, by the definition given by O'Reilly (2005) as the language of inclusion and exclusion implies a binary logic, that one is either excluded 
or included in relation to some variable. The question of inclusion, therefore, is best conceptualized as a sort of sliding scale rather than a binary function, so that exclusion and inclusion are the extreme poles of a continuum relation of inclusion and exclusion (O'Reilly, 2005). Social exclusion is a multidimensional process of progressive social rupture, detaching groups and individuals from social relations and institutions and preventing them from full participation in the normal, normatively prescribed activities of the society in which they live (Silver, 1994).

\section{Reservation Policy: The Context of Nepal}

In the context of Nepal, (Gurung, 2007) argues that the social organization on the basis of hierarchical caste system as the main cause for exclusion. Also, the political ideology of Nepal as a Hindu country that sanctified caste system remained highly exclusionary. Similarly, Jamil \& Dangal, (2009) have stated that the bureaucracy of Nepal is basically gender biased, caste biased, language biased, religion biased and geographically biased in terms of demography. We came to know that without the active participation and representation of men and women at all levels of decisionmaking, especially in governance, we cannot achieve the goals of equality, development, and peace Haque, (2000). Reflecting this global trend, female representation in governance has been quite poor in most Asian countries. In addition to the sustainable development of mentioned groups were categorized for social inclusion in civil service to women, indigenous (Adibasi/Janajati), Madhesi and Dalit people of Nepal, whereas there are two more categories distinguished as people from remote regions and physically disabled people for the same. The following nine districts out of seventy-seven regions fall under the category of the remote regions: Kalikot, Dolpa, Mugu, Jumla, Humla, Achham, Jajarkot, Bajhang and Bajura. People from these backward regions have been provided with $4 \%$ of the reserved quota in the process of recruitment of employee in civil service.

Civil Service Act, 1991, Article 21 states that women, Dalits, Adibasi/Janajati's, the Madhesi community, downtrodden classes, poor farmers, and workers who have lagged behind from the economic, social or educational viewpoint shall have the right to participate in the state structure based on the principle of proportionate representation. Then, in August 2007, the second amendment to the 1992 Civil Service Act provided for reserving 45 per cent of all vacancies to be fulfilled by way of open competition and, assuming the vacancies thus reserved to be 100 percent, fulfilling the same by way of separately-held competitions from among each of the six specified categories of candidates: Women (33 percent), Adibasi/Janajati (27 percent), Madheshi (22 percent), Dalit ( 9 percent), persons with disability ( 5 percent) and those from the backward areas (4 percent). The Civil Service (Second Amendment) Act, 1991, in 2007 has since formed a reference for other public services and similar, if not the same, provisions have been made in security services, university services and so on. Many factors seem to be at work in achieving representative public administration beyond the arithmetic of reservation, however. Finding them out and addressing them together should be part of the reform agenda for Nepalese bureaucracy.

\section{Research Methodology}

This article adopted mixed method having both qualitative and quantitative approach. Therefore, the descriptive method has been found suitable and hence adopted for this study on the basis of the selected research topic, prescribed objective and set research questions. The units of observation involve various government organizations under different ministries of Government of Nepal. There are 88,316 civil servants working in the civil service of Nepal (2076/03/31). The sample among this population on the basis of convenience and judgmental sampling basis. The data and information is collected from the discussions, interactions and articles review shed light on the various issues related to this subject matter. The dependent variable of this article is effects of reservation policy in the today's civil service of Nepal with maintaining the merit system is influenced by the various independent variables these can be such as participation of disadvantaged group, ownership of weaker society, empowerment of marginalized communities, attraction to civil service and status of reserved groups and so on. The data and information have been collected prior consideration of the defined dependent and independent variables.

For gathering primary data, a questionnaire survey was carried out to Office of the Auditor General (OAG), Nepal and Public Service Commission (PSC) Nepal. Similarly, other methods of primary data collection include nonparticipatory observations, and the participatory interviewed methods. In order to show the linkage between primary and secondary data, content analysis was conducted from the observational notes, field notes, and responses collected by open-ended as well as closed ended questionnaire. For questionnaire survey, total number of respondents were 130 (including 6 key respondents were interviewed). In this article the purposive and quota sampling is used and the researcher has set the questionnaire in statement form of the study. A 4(four) point Likert scale was used to apply value for the categorical data and further this scale was again recoded into two scales for the further analysis. IBM SPSS 25 version was used to gather frequency, percentage, and cross tabulation of the survey. Along with it, the bivariate analysis was done to show the linkage between dependent variable and independent variable. The bivariate analysis between dependent variable and independent variable shows the effects of gender, age and education matters in inclusiveness of civil service i.e. there is high relationship between these variables. 


\section{Result and Discussion}

\section{Effects of Gender, Age, Education and Position into the Civil Service of Nepal}

This article deals with the relationship of gender, age and education with the. Though there are many factors which comes under Scio-demographic factor, but here the researcher has only taken gender, age, educational qualification, and entry level position of the respondents as important variable for desired study. Therefore, the relationship between Scio-demographic factors with the inclusiveness is listed in Table 1.

The first variable which is gender. The Table1 shows the relationship between gender and inclusiveness. There are altogether 130 respondents, when gender and representativeness is crosstab, then the Table 1 shows that $62 \%$ of female respondents agree that gender has more to deal with inclusiveness while in case of male respondents only $79 \%$ of the respondents agree about it. The bivariate analysis of the Table 1 shows that when gender and inclusiveness was crosstab than we got the value of chi square as 9.732 and $p=0.021$ which means that there is high relationship between these two variables and are statistically significant at 0.05 . From this analysis, we can conclude that there is strong relationship between the gender of the respondents and inclusiveness and plays the crucial effects into the sense of inclusion.

Khadka \& Sunam (2018) in their paper "Workforce diversity and reservation policy in Nepal: A strategic approach to strengthening women's voice and visibility in formal employment sector" has presented that Nepal's good policy measures of gender and social equality, affirmative action policies have not only increased women's representation and visibility in government employment and the employment in development industries, it has also created opportunities for women to express their voices in their organizations which can potentially make a difference in development and institutional transformational process in the country's federalization systems. However, it is not enough just to have women's engagement in the public service their effective participation in policy making and decision-making need to be reinforced through gender awareness training, gender budgeting and gender mainstreaming training and other mechanisms that policy making and the allocation of resources is gender responsive.

The second variable is age. Here in the survey the age of the respondents is collected in years than it was classified into age group between before 35 and after 35 . In order to see how the age affects the notion of representativeness, the bivariate analysis is used. From the Table 1, it is clear that maximum number of respondents belongs to before 35 age group and $55 \%$ of the respondents agree that age have crucial role in the inclusiveness of civil service of Nepal. The bivariate analysis of the Table 1 shows that there is no relationship between age of the respondents and the inclusiveness. When age and inclusiveness was crosstab than the findings indicate that the given variable are not statistically significant at 0.05 (chi square 0.676 and $p=$ .879). It means age doesn't matter in case of inclusiveness.

In the survey, the third variable is education, there are 57 respondents who have bachelor degree and 66 respondents who have master degree. Here, in this survey who have minimum qualification (i.e. $75 \%$ ) agree that minimum requirement of education have crucial role in inclusiveness than in comparison to those who have master degree. The reasons may be as the level of the education is determining factor for the upward movement of the respondents and it can also provide more opportunities in comparison to the less educated person. The Table 1 of bivariate analysis shows that the education and inclusiveness are not statistically significant as the value of chi square is 6.333 and $\mathrm{p}=.378$. It indicates that both the variable has no relation at all. It can be interpreted in such a way that the minimum educational qualification for the gazette post is bachelor degree and only that candidate will apply for the job. Therefore, the foremost requirement is bachelor degree but if some have the master degree it will be the plus points for the new candidates for upward movement easily than those who have only bachelor degree. Therefore, the entry level positions of the respondents do not have much to deal with the inclusiveness.

Table 1: Effects of Gender, Age and Education in Inclusiveness of Civil Service

\begin{tabular}{|c|c|c|c|c|c|c|}
\hline \multicolumn{2}{|l|}{ Variables } & \multicolumn{5}{|c|}{ Inclusiveness of Civil Service of Nepal } \\
\hline & & \multirow[t]{2}{*}{ Number of Respondents } & \multicolumn{2}{|c|}{ Percent (\%) } & \multicolumn{2}{|c|}{ Chi-Square Test } \\
\hline & & & Agree & Disagree & Value & Sig. Level \\
\hline \multirow{2}{*}{ Gender } & Male & 95 & 79 & 21 & \multirow[t]{2}{*}{9.732} & \multirow[t]{2}{*}{0.021} \\
\hline & Female & 35 & 62 & 38 & & \\
\hline \multirow[t]{2}{*}{ Age Group } & Before 35 & 104 & 74 & 45 & \multirow[t]{2}{*}{0.676} & \multirow[t]{2}{*}{0.879} \\
\hline & After 35 & 26 & 77 & 33 & & \\
\hline Educational & Bachelor & 57 & 71 & 29 & \multirow[t]{2}{*}{6.333} & \multirow[t]{2}{*}{0.378} \\
\hline Qualification & Master & 66 & 79 & 21 & & \\
\hline \multirow[t]{2}{*}{ Level/position } & Officer & 70 & 76 & 24 & \multirow[t]{2}{*}{3.252} & \multirow[t]{2}{*}{0.354} \\
\hline & Non-Office & & 73 & 27 & & \\
\hline
\end{tabular}

(Source: Field Survey, 2020) 
In the given survey, the fourth variable is position and 70 respondents are gazetted officer posts while only 60 respondents enter through non-officer. Similarly, the nature of agree and disagree between gazette and non-gazette officer differs slightly so it can be interpreted in this way that the reservation system has been very helpful and the target group have been able to come into mainstreaming while some of the respondents do not agree on it. Due to this policy, many disadvantage groups are able to get full benefit from it. Likewise, in the survey 78 respondents have entered the civil service regarding the benefit of inclusiveness. In this regard, one of the major reasons behind this may be some of the respondents has been benefited by this policy and they are able to enter in the civil service in the gazette and non-gazette posts. When the entry level position of the respondents and inclusiveness was crosstab then the findings where its chi square value is 3.252 and $p$ is 0.354 , which means that these variables are not statistically significant. It means entry level position do have much more to deal with the inclusiveness as the desired people have already enter in the civil service whether from the gazette post or from non- gazette post. Therefore, the upward movement of their career entirely depends upon him/her competences.

In this discussion, there exists a wide gender, caste and regional gap between men and women in all development aspects such as social, economic, political and educational sectors. it has been most pronounced about who are targeted people and whether the targeted people are included by the policy or not? The need of this policy was felt and brought for the purpose of realizing social inclusion into the civil service of Nepal. But few people are not happy with the implementation part of the policy as the real targeted people are not being included and problems of the real targeted people are still in exclusion. But, according to the previous discussions, in the name of those marginalized and deprived people, the elites of those groups are taking the benefits.

\section{Organizational Effects of Reservation System in Nepal}

Here, this article examines an organizational effect refer to the administrative culture, structure, chain of command,

Table 2: Organizational Effects on Reservation System in Civil Service of Nepal

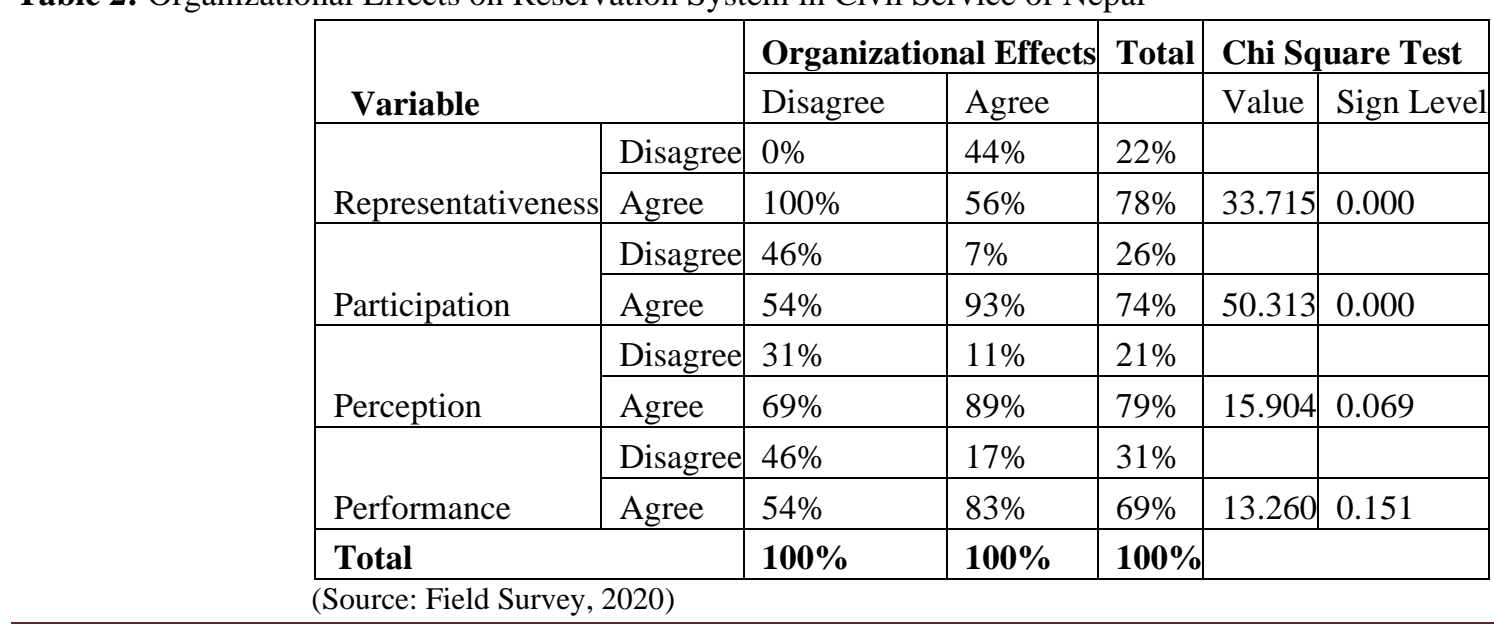

(Source: Field Survey, 2020) professionalism, rules and regulation, job recognition, participation, performance, attitudes, and challenges of the respondents towards the organizations. In addition, Reskin (1998) has identified the additional benefits of proactively preventing discrimination, and increasing organizational diversity to enhance creativity, innovation, and organizational success. On the basis of the given key variables, the perception of the respondents was analyzed, which are regarded as strong determining factor to achieve the desired targets in the respective public organization. It means the respondents are able to utilize their own potential whatever the organizational opportunities are provided to them and the respondents are fully benefitted by it and it is very helpful to enhance their capacity. Based on these key points, five set of question related to the organizational effects are asked to the respondents. This bivariate analysis deals with relationship between the reservation system application and its organizational effects are highlighted in Table 2.

According to the Table 2, the first variable shows the relationship between representativeness and its organizational effects. In case of reservation system, nearly majority respondents i.e. $78 \%$ agree that the policy is very crucial weapon to recover the deprived people to make the civil service more representative more deliberative during their organizational framework to make them inclusion. Here, the bivariate analysis of the Table 2 also supports that there is strong and significant relationship between representativeness and its organizational effects in civil service. Similarly, the calculated value of chi square is 33.715 and $p=.000$, which shows somehow very significant relationship that the respondents agree that until the representativeness promotes the uncovered and reserved candidates into the civil service for the national sociocultural harmony, bureaucratic democracy and gender, caste and regional inclusion into the organizational structure and it plays very crucial role in the socio-cultural achievement for inclusive civil service of Nepal. 
The second variable shows the relationship between participation and its organizational effects. In case of level of decisional participation, mostly respondents i.e. $74 \%$ agree that they are high level of participation promotes the organizational inclusion, rule and regulation adaptation, decisional ideas for the complex problem solving of sociocultural debates and disputes settlement into the civil service system of Nepal. The major reasons behind the participation is to maintain the performance standard, make learning, adjustable and motivated civil servants to accept the gender, caste and disable friendly working environment into civil service of governance of Nepal. Here, the Table 2 also supports that there is strong and significant relationship between participation and organizational inclusion and very supportive and friendly working behaviors into the civil service of Nepal. Similarly, the calculated value of chi square is 50.313 and $\mathrm{p}=.000$, which shows somehow strong and significant relationship that's why most $74 \%$ respondents agree that participation of reserved people have the strong value to make the working environment of civil service more friendly, supportive and inclusive structure to give respect and opportunities for the organizational democracy which motivate the disadvantaged people into the civil service of Nepal.

The third variable shows the reservation perception and its organizational effects. In case of level of positive attention, nearly most respondents i.e. $79 \%$ agree that they are very high level of representation of disadvantaged people into the civil service is helping to balance the dominance of Brahaman and Chhetri's male civil servants, biasness of office system, physical discrimination, caste hegemony and perceptional unacceptance to public organization that leads cooperative organizational effects into the civil service of Nepal. Here, Table 2 also supports the discussed argument that there is no significant relationship between reservation/inclusion perception and its organizational effects into the civil service. Similarly, the calculated value of chi square is 15.904 and $p=.069$, which is more than 0.05 and it shows somehow less significant between them but at the same time the $21 \%$ of the respondents disagree that organizational factor like elite capture system, discrimination office culture, low motivating outlook of public organization are still exist into the public bureaucracy and that be the challenge and hindrance in the achievement of inclusive and representative civil service of Nepal.

The forth variable shows the relationship between performance of reserved people and its organizational effects. In case of equal treatment and support, most of the respondents i.e. $69 \%$ agree that they are performance of reserved facilitated employees with the equal responsibilities and leadership role promotes the organizational recognition and reward into the civil service of Nepal. The major reasons behind the performance is to teach equally, support equally, behave equally into the office working environment and motivate them to take crucial challenges with the full authority and supervisor support into the civil service. Here, the Table 2 also supports that there is no significant relationship between performance of women and deprived people and its organizational compliance but for the effectiveness of civil service there should be first representation of targeted people of reservation system into the civil service of Nepal. Similarly, the calculated value of chi square is 13.260 and $\mathrm{p}=.151$, which shows somehow less significant relationship between the performance and organizational structure that's why most $31 \%$ of the respondents agree that performance of reserved people is not the matter but initially they must be incorporated into the civil service system to deliver performance regarding public service competently that positively effects of deprived people into public organization of civil service of Nepal. Observing the effects of affirmative action can provide useful guidance on what contributes to public organizations' performance. For example, increasing functional diversity, merit-based selection and employees' morale are all supposed to improve organizational performance. Through increasing social diversity, affirmative action also promotes functional diversity (Schneider and Northcraft, 1999). So, the performance of organizations implementing affirmative action should improve over time of policy.

\section{Current Position of Reservation System in Civil Service of Nepal}

The reservation policy in public service has been adopted with the objective of (i) creating a representative public service (ii) mainstreaming excluded people from different class groups, caste/ethnic groups, regions and communities, and engaging them in nation building activities (iii) projecting existing public service scenario, and (iv) narrowing down the gap between the dominant and excluded groups (Awasthi \& Adhikari, 2012). Reservation is a form of affirmative action designed to improve the participation of under-represented communities defined primarily by gender, caste, backwardness and disability. Reservation based on gender, caste, backwardness and disability are laws both Constitutional and statutory. The advent of democracy in 1951 ushered in many changes in Nepal. Until then the demand for inclusion was part of and perhaps overshadowed by the broader civil rights movement. Democracy brought with it equal rights for all citizens regardless of gender or other forms of social grouping. In this regard, the current status of reservation system and its practices were analyzed. Though, a gap in the implementation of the policy is seen, there is some room for contentment as the process of including and recruiting the excluded groups through Public Service Commission has begun. This analysis helped me to study the overall trend of the affirmative policy implementation in Civil Service. The 
issues on the inclusiveness in the Nepalese Civil Service were analyzed and these are more likely to be addressed for the reduction of exclusion from the Civil Service. For this reason, the reservation policy has been implemented in Nepalese civil service since 2064 through the amendment in the civil service act 2049. The constitution of Nepal gives the mandates to make special provisions by law for the protection, empowerment or development of the citizens including socially or culturally back warded classes. So the trend and current condition of implementation in civil service of Nepal since F/Y 2064/065 to onward. Finally, I have presented the scenarios of representation since last twelve years. That can be shown Table 3 .
Before the reservation policy implementation, the female participation was $11 \%$ at the end of Ashadh, 2065. Coming to the year 2075/076, the participation of male was $74.07 \%$ and female was $25.94 \%$. Nepal's ethnic diversity is not reflected in civil service. It has been a decade since Nepal adopted a policy of reservation to promote inclusion, but the government still lacks official figures about representation of various ethnic groups in civil service. The pattern of female participation is in gradually increasing form after the implementation of reservation policy and they are now advocating and empowering their own right and employment independently. That's why the today's civil service is becoming somehow inclusive and representative with number increment of marginalization community.

Table 3: Current Status of Reservation System in Civil Service of Nepal

\begin{tabular}{|c|c|c|c|c|c|c|c|c|}
\hline \multirow{2}{*}{$\begin{array}{c}\text { Fiscal Year } \\
12 \text { years }\end{array}$} & \multirow[t]{2}{*}{ Open Quota } & \multicolumn{7}{|c|}{ Employees Selected from Reserved Quota } \\
\hline & & Women & Janajati & Madhesi & Dalit & Disables & Remote & Total \\
\hline $2075 / 076$ & 2394 & 625 & 509 & 409 & 168 & 95 & 77 & 1883 \\
\hline $2074 / 075$ & 4007 & 1088 & 858 & 711 & 292 & 163 & 132 & 3244 \\
\hline $2073 / 074$ & 5273 & 1383 & 1026 & 901 & 385 & 189 & 142 & 4026 \\
\hline $2072 / 073$ & 3300 & 797 & 629 & 503 & 213 & 101 & 95 & 2338 \\
\hline $2071 / 072$ & 2783 & 639 & 547 & 454 & 168 & 95 & 76 & 1979 \\
\hline $2070 / 071$ & 2767 & 626 & 509 & 384 & 173 & 91 & 71 & 1854 \\
\hline $2069 / 070$ & 1707 & 372 & 318 & 254 & 106 & 51 & 35 & 1136 \\
\hline $2068 / 069$ & 1805 & 352 & 280 & 212 & 99 & 40 & 30 & 1013 \\
\hline $2067 / 068$ & 2487 & 471 & 371 & 300 & 105 & 59 & 43 & 1349 \\
\hline $2066 / 067$ & 2080 & 495 & 368 & 319 & 142 & 64 & 43 & 1431 \\
\hline $2065 / 066$ & 840 & 117 & 94 & 91 & 36 & 15 & 12 & 365 \\
\hline $2064 / 065$ & 2228 & 366 & 245 & 183 & 84 & 33 & 17 & 928 \\
\hline Grand Total & 31671 & 7331 & 5754 & 4721 & 1971 & 996 & 773 & 21546 \\
\hline
\end{tabular}

(Source: Public Service Commission, 12 years Reports, 2077)

Table 4.: Gender Differences after 12 Years in Different Level Civil Service of Nepal

\begin{tabular}{|c|c|c|c|c|c|c|c|c|c|c|}
\hline \multirow[b]{3}{*}{ Class } & \multicolumn{5}{|c|}{$2064 / 65$} & \multicolumn{5}{|c|}{ 2076/77 } \\
\hline & \multicolumn{2}{|c|}{ Men } & \multicolumn{2}{|c|}{ Women } & \multirow[t]{2}{*}{ Total } & \multicolumn{2}{|c|}{ Men } & \multicolumn{2}{|c|}{ Women } & \multirow[t]{2}{*}{ Total } \\
\hline & Number & $\%$ & Number & $\%$ & & Number & $\%$ & Number & $\%$ & \\
\hline Chief Secretary & 1 & 100 & 0 & 0 & 1 & 1 & 100 & 0 & 0 & 1 \\
\hline Special Class & 60 & 100 & 0 & 0 & 59 & 67 & 95.71 & 3 & 4.29 & 70 \\
\hline Gazetted First & 463 & 94.88 & 25 & 5.12 & 488 & 522 & 92.88 & 40 & 7.12 & 562 \\
\hline Gazetted Second & 3160 & 95.18 & 160 & 4.82 & 3320 & 2985 & 92.02 & 259 & 7.98 & 3244 \\
\hline Gazetted Third & 9537 & 89.77 & 1087 & 10.23 & 10624 & 8357 & 84.17 & 1578 & 15.83 & 9929 \\
\hline Non-gazetted & 23963 & 85.78 & 2973 & 14.22 & 27936 & 21106 & 80.99 & 4953 & 19.01 & 26059 \\
\hline Classless & 17705 & 95.25 & 1487 & 7.75 & 19192 & 11667 & 90.55 & 1218 & 9.45 & 12885 \\
\hline Health Service & 11557 & 59.44 & 7885 & 40.56 & 19442 & 13676 & 58.2 & 12620 & 41.8 & 26296 \\
\hline Justices/judges & 298 & 97.39 & 8 & 2.61 & 306 & 335 & 93.84 & 22 & 6.16 & 357 \\
\hline State/Local level & 0 & 0 & 0 & 0 & 0 & 6689 & 75.05 & 2224 & 24.95 & 8913 \\
\hline Total & 66743 & 82.03 & 14625 & 17.97 & 81368 & 65405 & 74.06 & 22917 & 25.94 & 88316 \\
\hline
\end{tabular}

(Source: Department of Civil Personnel Records, Hariharbhavan, Lalitpur, Ashadh 2077) 
Before the implementation of reservation policy in 2064/065, the representation of female in special class was zero. In first class was 5.12 percent, in second class was 4.82percent, in third class was 10.23 percent, and in non gazetted first-class 14.22 percent. Excluding health service and judge, in gazetted level, $90 \%$ were male and $10 \%$ were female. In non gazetted level, $88 \%$ were male and $12 \%$ were female. The total participation of male was 89 and female was $11 \%$ excluding health service and judge. In health service, in the FY 2064/065, the representation of female was around $41 \%$. The percentage of participation in the health service in comparison to the civil service shows higher because some of the posts like staff nurse, assistant nurse midwife in the health services is only for women. In Judiciary service, $97.39 \%$ male and very negligible $2.61 \%$ female were judge. The total participation of female in the civil service including health and judge service is $18 \%$.

After the twelve years of implementation of reservation policy in $2076 / 077$, the representation of female in special class is $4.29 \%$ in first class is $7.12 \%$, in second class is 7.98 $\%$, in third class was $15.83 \%$, in non gazetted first class $19.01 \%$ and in non gazetted second class is $17.45 \%$. Excluding health service and judge, in gazetted level, $87 \%$ were male and $13 \%$ were female. In non gazetted level, 87 $\%$ were male and $13 \%$ were female. The total participation of male was $87 \%$ and female was $13 \%$ excluding health service and judge. The representation of female in health service increased to $40 \%$ from $41 \%$ and judge is $4 \%$. The total participation of female in the civil service including health service and judge is $24 \%$. The Table 4 shows that before the implementation of reservation policy, in the F/Y 2064/065, excluding health service and judge, the total participation of female in the civil service was $11 \%$ and after the decade of the implementation of reservation policy, in the F/Y 2076/077, the total participation of female is $13 \%$. Including health service and justice, the total participation of female in the civil service was $18 \%$ and after the decade of the implementation of reservation policy, in the F/Y 2076/077, the total portion of female is $25.94 \%$. Excluding health service and judge, the percentage growth of female in the twelve years' period is $3 \%$.

\section{Major Findings}

The Interim Constitution, 2063 provisions and Civil Service Act 1993 (second amendment in 2007) has made a provision for reservation system in 2064 BS. Before this reservation policy introduced in Nepal, share of women in civil service only $11 \%$. Shares of Dalit, Muslim and disabled were virtually almost zero. Adivasi/Janajatis, Madhesis and Khas/Arya of remote area people had slightly higher shares. Further while analyzing the female's participation in Nepalese Civil Service, it was remarkably low participation of women in terms of population portion. In 2003, overall 8 percent of the women has been participated in civil service examination. Likewise, they were 15 percent in 2010 and 18 percent in 2015. In 2076/077 (2020), after 12 years of implementation of reservation system the shares of women in civil service is increased to $25.94 \%$ and shares of Adivasi/Janajatis, Madhesi's, Dalit, Muslim, disabled and remote area's people is also moderately accumulating in terms of numerical representation in the civil service of Nepal.

Based on the sequential explanatory study done to shows that among 130 respondents, above $85 \%$ agree that the principle of proportional representation and participation is fully ensured in the civil service and remaining respondents disagree about it. Perception of respondents was collected and measured by using Likert scale measurement. The survey shows that nearly all the respondents agree that disadvantage group feel to be included in the mainstream into the civil service in Nepal. Along with it, all the respondents agree that the targeted group have been able to utilize the opportunities provided in the civil service act and the constitution has guarantees equal opportunity to employment for all people and avoids discrimination. In case of perception towards the reservation, more than $70 \%$ of the respondents agree that male has more superiority complex and negative attitudes towards female. It means that the male has more superiority complex and negative attitudes towards female. Similarly, $85 \%$ of the respondents agree that special arrangement for male friendly are absent in the organization environment. Finally, the majority of the respondents i.e. above $80 \%$ disagree about the people from reservation are not capable to delivering the quality service in comparison with other people in workplace.

\section{Organizational Effects of Reservation Policy}

In the article, the organizational factor refers to the Office structure, working channel, rule and process, performance challenges and evaluation, motivation, coordination, leadership, responsibility, support, decision making and the satisfaction level of respondents towards the organization after the application of reservation system in Nepal. The findings of the survey show that, there was highly significant relationship between organizational effects of reservation system for the inclusiveness and the variable of representativeness and participation in civil service of Nepal. In the bivariate analysis, the calculated value of representation chi square is 33.0715 and $\mathrm{p}=.000$ and calculated values of participation chi square is 50.313 and $\mathrm{p}=.000$ and which shows highly significant relationship of independent variables with the inclusive civil service. The organizational effects of reservation for the perception and performance shows that there is less significant relationship with the inclusiveness of civil service of Nepal. Therefore, we can conclude that there is high relationship between organizational effects of reservation system and inclusiveness of civil service of Nepal. 
Hence, this article shows that the measurable and reliable indicators of inclusive civil service of Nepal which has the equitable opportunity for representativeness, participation and mainstreaming of the target group for the positive changes and cultural friendly organizational environment. Therefore, my research determination was not to advocate whether reservation system is good or bad. I have explained what the policymakers, implementers, beneficiaries and other people expecting in the society that have perceived regarding the implementation of reservation system in Civil Service of Nepal, and at the same time I also explored what the effects and current position of the implementation is and what the tendency of inclusion in Civil Service if Nepal is. Unless and until the individuals and group of people perceive the policy positively, the implementation part cannot give a sound output and consequence. In other words, the attitude of stakeholders regarding policy highly affects the practice. Therefore, my focal ambition of the research is to examine the policy effects and practical obstacles of reservation policy in Civil Service along with the deep understanding and commitment of how all the stakeholders have perceived the reservation policy in Nepal.

\section{Conclusion}

For the conclusion, the effects of the reservation policy is imposing the social, cultural, ethnic, economic and regional diversity reflection in civil service of Nepal. Historical dominance of one caste group in civil service is gradually balancing with other disadvantaged people. The participation of women and disadvantaged people in civil service is gradually increasing after the application of reservation system. When the civil service becomes more inclusive, government services have become more accessible to diverse communities, and sense of their ownership towards civil service is increasing. For this, proportional representation of all communities in state organs including civil service is the key to recognition, participation and overall inclusive consideration. This is the purpose of recent political changes, and this ideal has been reinforced by the constitution and several international laws endorsed by the Nepal.

Therefore, the reservation policy is being more popular and scientific, and the state must prepare acts/laws regarding policy to strengthen relations between the nation and marginalized communities with conducive environment. And all the respondents agree that the targeted group have been able to utilize the opportunities provided in the civil service act and the constitution has guarantees equal opportunity to employment for all people and avoids discrimination. Whereas $85 \%$ of the respondents agree that special arrangement for male friendly are absent in the organization environment. According to crosstab analysis, the individual effects of reservation for the inclusiveness shows that there is highly significant relationship between the individual participation and individual performance with the inclusiveness of civil service. An organizational effects of reservation system for the inclusiveness shows that there is highly significant relationship with the representativeness and participation in civil service of Nepal. It has the positive impacts in civil service elsewhere Nepal's affirmative action policy is not free from criticism. Critics suggest that reservation has benefitted women and men from the privileged castes and ethnic backgrounds, and thus women and men from rural areas of underprivileged caste/ethnic groups are still excluded. Finally, the policy has been made by top-down approach according to which it is very difficult to empathize with the native characteristics of the real targeted people. The need of educational trainings and applicable infrastructures related to attitude change and development of anti-discriminatory thought in every level of Civil servants has been realized the sense of humanity, respect and coexistence of other through reservation policy.

\section{Acknowledgements}

This article work has been undertaken by the author with the grant of University Grants Commission (UGC) with the funds made available for M.Phil. fellowship award. The opinions expressed herein, however, are those of the author and do not in any way represent views of the people and organizations named above.

\section{References}

Awasthi GD \& Adhikary R (2012) Changes in Nepalese civil service after the adoption of inclusive policy and reform measures. Support to participatory constitution building in Nepal.

Bhandari U (2012) Rethinking social inclusion in TEVT in Nepal. Nepal: Kathmandu University.

Civil Service Act $2049 \quad$ B.S. (1993). http://www.ilo.org/dyn/travail/docs/580/Civil\%20Service \%20Act.pdf (accessed on 20 February, 2020).

Constitution of Nepal, 2072 (2015). Retrieved from: http://www.satp.org/satporgtp/countries/nepal/document/ papers/Constitution_of_Nepal_2015.pdf (accessed on 12 February, 2020).

Figueiredo JB \& Gore C (1997) Social exclusion and anti-poverty policy: A debate. Geneva: International Labour Organization .

Foley D \& Chowdhury J (2007) Poverty, social exclusion and the politics of disability: care as a social good and the expenditure of social capital in Chuadanga, Bangladesh. Social Policy \& Administration 41(4): 372-385.

Francis P (1997) "Social capital, civil society and social exclusion" in Kothari, Uma and Matin Minouge (eds) "Development theory and practice: Critical Perspectives" Hampshire: Palgrave.

Goggin ML, Bowman A, Lester J and O'Toole LJ. Jr. (1990) Implementation theory and practice: toward a third generation. Glenview, D1.: Scott, Foresman/Litde, Brown. 
Gurung H (2007) From exclusion to inclusion: socio-political agenda for Nepal (pp. 1-53). Lalitpur: Social Inclusion Research Fund.

Haque MM (2000) Road planning and engineering for promoting pedestrian safety in Bangladesh. 10th REAAA Conference, September, REAAA, Tokyo.

Hicks T (2014) Partisan governance and policy implementation: The Politics Of Academy Conversion Amongst English Schools. Journal of Public Administration 92(4): 9951016.

Hill MJ, Hupe PL (2014) Implementing public policy: an introduction to the study of operational governance, (3rd ed). London: Sage.

Interim Constitution of Nepal (2007) Kathmandu: Nepal Law Commission. Available at: http://www.wipo.int/wipolex/en/text.jsp?file_id=189180 (accessed on 10 February, 2020).

Jamil I \& Dangal R (2009) The State of bureaucratic representativeness and administrative culture in Nepal. Contemporary South Asia 17(2): 193-211.

Jamil I and Dangal R (2009) The State of bureaucratic representativeness and administrative culture in Nepal. Contemporary South Asia 17(2): 193-211.

Khadka M \& Sunam R (2018). Workforce diversity and reservation policy in Nepal: a strategic approach to strengthening women's voice and visibility in formal employment sector. In women and the future of work in the Asia-Pacific.

Krook ML (2010) Women's representation in parliament: a qualitative comparative analysis. Political Studies 58(5): 886-908.
Nepal Population Report. (2018) Nepal national population report 2011 \& 2018. Kathmandu, Nepal: Government of Nepal Ministry of Health and Population Division Ramshahpath.

OECD (2014) Women, government and policy making in oecd countries: fostering diversity for inclusive growth. Available https://uweboard.files.wordpress.com/2014/08/womengovernment-and-policymaking.pdf (accessed on June 11, 2016)

Omvedt G (2008) Caste is the cruelest exclusion: agenda against exclusion: The roots of social exclusion and battle against it (13).

Oommen TK (2010) Evolving inclusive societies through constitutions: the case of Nepal. Contributions to Nepalese Studies 37(1): 1-16.

O'Reilly D (2005) Social inclusion: A philosophical anthropology. Politics 25(2): 80-88.

Schneider SK, Northcraft GB (1999) Three social dilemmas of workforce diversity in organizations: A social identity perspective. Human Relations 52(11): 1445-1467.

Silver H (1994) Social exclusion and social solidarity: three paradigms. International Labour Review 133: 531-578.

Stewart JJ, Hedge DM \& Lester JP (2008) Public policy: An evolutionary approach (3rd ed.). Boston: Thomsom Wordsworth.

Van Meter D and Van Horn CE (1975) The policy implementation process: A conceptual framework. Administration and Society 6(4): 445-488

World Bank (2018) The world bank annual report 2018. The World Bank. 